\title{
A summary of hazard datasets and guidelines supported by the Global Earthquake Model during the first implementation phase
}

\author{
Marco Pagani ${ }^{1, \star}$, Julio Garcia $^{1}$, Damiano Monelli1 ${ }^{1,2}$, Graeme Weatherill ${ }^{1}$, Anselm Smolka ${ }^{3}$ \\ ${ }^{1}$ GEM Hazard Team, GEM Foundation, Pavia, Italy, hazard@globalquakemodel.org \\ ${ }^{2}$ Now at Tokyo Millenium Re, Zurich, Switzerland \\ ${ }^{3}$ Secretary General, GEM Foundation, Pavia, Italy
}

Article history

Received October 2, 2014; accepted November 24, 2014.

Subject classification:

Earthquake faults, Ground motion, Seismic risk, Global datasets, Seismic hazard, Global earthquake model.

\begin{abstract}
The Global Earthquake Model (GEM) initiative promotes open, transparent and collaborative science aimed at the assessment of earthquake risk and its reduction worldwide. During the first implementation phase (2009-2014) GEM sponsored five projects aimed at the creation of global datasets and guidelines toward the creation of open, transparent and, as far as possible, homogeneous hazard input models. These projects concentrated on the following global databases and models: an instrumental catalogue, a historical earthquake archive and catalogue, a geodetic strain rate model, a database of active faults, and set of ground motion prediction equations. This paper describes the main outcomes of these projects illustrating some initial applications as well as challenges in the creation of hazard models.
\end{abstract}

\section{Introduction}

The Global Earthquake Model (GEM) initiative is a public-private effort which currently involves sixteen countries and eleven private organizations from the engineering, insurance and public/governmental sectors. GEM promotes an open and transparent assessment of seismic hazard and risk based on state-of-the-art datasets and methodologies.

The first implementation phase started in 2009 and concluded at the end of 2014, saw GEM sponsor five projects aimed at the creation of global, homogenous datasets supporting the development of new hazard models and, in general, research in the seismological sector. These projects - called global components - covered the most important research areas for the characterization of the earthquake process such as historical seismicity, instrumental seismicity, strain rate modelling, earthquake geology and ground motion modelling. Five global projects were also promoted in the field of the physical risk assessment [Crowley et al. 2013].
With the same aim of actively encouraging reproducibility and transparency in seismic hazard model creation process, GEM also developed an extensive opensource library of tools for the preparation of Probabilistic Seismic Hazard Analysis (PSHA) models and for the calculation of hazard. This library includes the OpenQuake hazard modeller's toolkit (HMTK), the OpenQuake Ground Motion toolkit (OQ-GMTK) and the OpenQuake-engine (which comprises the OpenQuake hazard library; Pagani et al. [2014]). The OpenQuake Hazard Modeller's ToolKit [Weatherill et al. 2012, 2014a] is a suite of tools for processing basic information, e.g., earthquake catalogues, active faults and geodetic strain, used for the characterization of the Seismic Source Model (SSM hereafter). Using the HMTK it is possible to create sources that can be incorporated into a source model for the calculation of hazard at a specific site. The OpenQuake Ground Motion Toolkit (OQ-GMTK; Weatherill et al. [2014b]) is the counterpart of the HMTK for the creation of the Ground Motion Models (hereafter GMM) for application in a particular analysis. It contains tools for the construction of a ground motion database starting from a set of processed recordings, for the calculation of ground motion residuals given a ground motion prediction equation (GMPE) and a collection of processed strong motion recordings, for the ranking of GMPEs using quantitative methods [e.g. Scherbaum et al. 2009]. Both toolkits integrate components of the OpenQuakeengine into the software, ensuring full consistency with OpenQuake-engine itself with regard to the application of GMPEs, representation of fault geometry and geodetic distances and the generation of ruptures.

In many areas of the world the results of the Global Seismic Hazard Assessment Programme (GSHAP; Giar- 
dini et al. [1999]) still represent a reference, or in some cases the only, quantitative assessment of hazard available, despite the progress made in the past twenty years in the comprehension of the earthquake process. The overall goal of GEM during its first implementation phase was therefore to create a set of tools, databases and guidelines, which could serve the creation of new and more harmonized Probabilistic Seismic Hazard Analysis (PSHA) input models and consequently provide to the broader community more updated assessments of seismic hazard. The auspice is that in the near future, local communities at regional and national levels will harmonize the information included in GEM's global datasets with more specific knowledge and will work in a collaborative effort at testing, applying and improving the guidelines, the methodologies and the tools created by GEM. Ideally, this should be a collaborative process directed at the creation of reliable and consistent models as well as at the collective progress of science within the seismic hazard assessment field.

During the first implementation phase some research projects operated as GEM regional programs i.e. independent projects directed at the creation of new datasets and hazard and risk models. These projects were: the Seismic Hazard Harmonisation in Europe (SHARE), the Earthquake Model for the Middle East (EMME) and the Earthquake Model for Central Asia (EMCA). SHARE [Giardini et al. 2014] produced an extensive group of updated datasets as well as a hazard model covering the entire European continent. The results have been released in 2013 and they are accessible though the project website (http: / / www.share-eu.org/, last accessed on September 2014). The EMME project (Sesetyan et al. [2014]; http:/ / www.emme-gem.org/, last accessed September 2014) created a hazard model covering a region spanning from the western coast of Turkey, though Iran and until Pakistan. Danciu and Giardini [2015, this issue] provide an overview of the SHARE and EMME projects emphasizing the issues connected with the harmonization of the two models at their mutual boundaries. Finally, the Earthquake Model for Central Asia (EMCA; Parolai et al. [2015, this issue]) created a community seismic hazard model for the area covering Turkmenistan, Kazakhstan, Tajikistan, Uzbekistan and Kirgizstan (additional information available on the project website, http: / / www.emca-gem.org/, last accessed on September 2014). These projects had been an extraordinary opportunity for testing the use of the OpenQuake-engine in the calculation of region-wide seismic hazard models. The SARA (South America Risk Assessment) Project, a new GEM regional program, sponsored by the Swiss RE Foundation, will be the first project in which GEM tools and datasets will be exten- sively tested for the creation of PSHA input model; the collaboration with the local scientific community will certainly help on improving the current tools.

This paper aims at illustrating the main datasets produced by the GEM global components, at briefly illustrating some recent research based on this datasets and on discussing how they can be possibly used for the construction of seismic hazard analysis input models.

\section{GEM hazard global components}

Three out of the five GEM hazard global components had the primary goal of developing global homogenous datasets - the global instrumental catalogue, global historical catalogue and active fault database while the other two worked on creating specific models (i.e. a strain rate model and a ground motion model). Most of the GEM hazard global components started their activities in 2010 and concluded their work between 2012 and 2013. The teams were composed by international groups of experts in order to guarantee to the extent possible global participation and the involvement of highly qualified scientists.

In the following sections we briefly summarize the main achievements of the five GEM Global Components.

\subsection{Global instrumental catalogue (ISC-GEM)}

The scientific project dedicated to the construction of a global uniform instrumental catalogue was led by the International Seismological Centre and saw the participation of a numerous and highly qualified group of international experts. The ISC-GEM catalogue [Storchak et al. 2012, 2013, 2015] covers the entire instrumental period (1900-2009) and is compiled considering information included in a vast number of catalogues (e.g. ISC Bulletin, Global CMT; Ekström et al. [2012]), in the literature [Lee and Engdahl 2015], new information ported from ISS paper bulletins into a digital format and new results produced within the project.

During the period 1900-1917, the ISC-GEM catalogue contains events with magnitude larger or equal to $7.5\left(\mathrm{M}_{\mathrm{S}}\right)$ worldwide, supplemented by a few tens of smaller shallow earthquakes in stable continental areas. From 1918 until 1959 the catalogue was compiled considering earthquakes whose magnitude was equal or larger than $6.25\left(\mathrm{M}_{\mathrm{S}}\right)$. The most recent part of the catalogue (starting from 1960 until 2009) includes events equal or larger than $5.5\left(\mathrm{M}_{\mathrm{S}}\right)$.

The earthquakes comprised in this catalogue were relocated following a homogenous approach entailing a first stage, where the hypocentral depth is computed using the EHB methodology [Engdahl et al. 1998], and a second stage where the epicentral location is obtained 


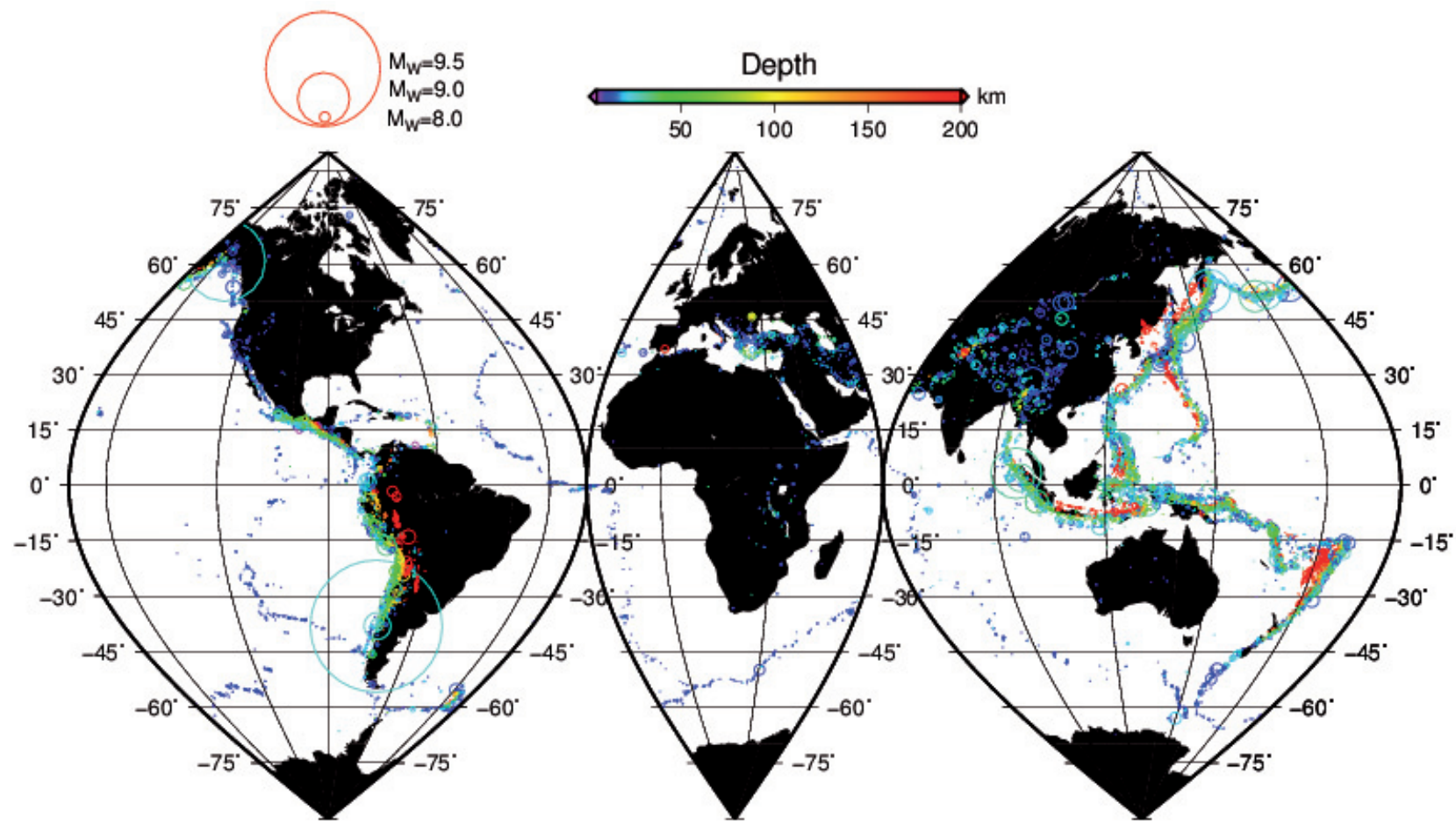

Figure 1. Geographic distribution of the epicenters included in the ISC-GEM catalogue. The color indicates the hypocentral depth.

with the application of the Bondar and Storchak [2011] algorithm.

Figure 1 shows the spatial distribution of the earthquakes (more than 18,800 in total) included in version 1.05 released in February 2014. The catalogue is updated by the ISC every time changes are introduced; a log of changes is maintained on the ISC website (http: / / www.isc.ac.uk/iscgem/update_log/).

The determination of magnitude for each earthquake followed a homogeneous methodology aimed at the compilation of a catalogue where the size of each event is defined in terms of moment magnitude. For this purpose seismic moment information already available (e.g. Global CMT catalogue - http:/ / www.global $\mathrm{cmt}$.org/) as well as data included in a vast body of literature was used to the largest extent possible; for the older events proxies, new regression models from other magnitude types were used as a primary method for magnitude harmonisation [see Di Giacomo et al. 2014].

Michael [2014] analysed the ISC-GEM catalogue in order to define the region of the magnitude-time space within which this catalogue can be considered complete (i.e. containing all the events occurred). The results of Michael show that the magnitude of completeness $\left(\mathrm{M}_{\mathrm{C}}\right)$ in the early instrumental era (i.e. between 1900 and 1917) for shallow seismicity - corresponding to the events with hypocentral depth lower than $60 \mathrm{~km}$ - is around 7.7. This threshold progressively decreases with time from 7.0 in the period between 1918 and 1939, going to 6.8 between 1940 and 1954. In its most recent part (i.e. between 2004 and 2009), the catalogue is complete above magnitude $5.7 \mathrm{M}_{\mathrm{w}}$. The green dotted line in Figure 6 shows the completeness thresholds for different periods in a time-magnitude plot.

Christophersen et al. [2013] used the ISC-GEM catalogue to analyze at the global scale the statistics of large aftershocks - i.e. earthquakes with a magnitude within 1.1 units from the mainshock - occurring at relatively short distance from the mainshock. The study had the goal to analyze the Darfield - Christchurch sequence in the context of global seismicity occurrence properties.

Hayes et al. [2013] analyze the earthquake and tsunamis potential of seismic sources in the Caribbean using the ISC-GEM catalogue in combination with other catalogues such as PDE (USGS), Global CMT [Ekström et al. 2012] and EHB [Engdahl and Villaseñor 2002].

Pollitz et al. [2014] use the ISC-GEM catalogue to investigate global seismic quiescence periods in the framework of a study aimed at assessing the short- and long-term triggering of seismicity produced by the M 8.6 Indian Ocean event occurred in April 2012.

Geist [2014] uses the ISC-GEM catalogue together with other earthquake catalogues to investigate through an Epidemic-Type Aftershock Sequence model the temporal clustering of seismic activity from seismic sources capable of generating tsunamis.

\subsection{Global historical earthquake archive (GHEA) and} catalogue (GHEC)

The determination of earthquake locations and magnitudes through the investigation of historical sources yielded in the past - and still provides - useful 
information for better constraining the properties of seismic occurrence [Guidoboni 2002]. In many countries in the world the information produced by these investigations still constitutes the primary dataset used for the characterization of seismicity occurrence in PSHA input models.

The Global Earthquake model sponsored a project called "Global Earthquake History" (GEH; Albini et al. [2014a, 2014b]) led by scientists of the Istituto Nazionale di Geofisica e Vulcanologia (National Institute of Geophysics and Volcanology, INGV, Italy) and the British Geological Survey (BGS, UK). This project produced an archive of historical seismicity studies and from this archive created a database of earthquakes occurring during the period 1000 C.E. and 1903 C.E. with magnitude equal or larger than 7 .

The Global Historical Earthquake Archive (GHEA) contains 3175 records extracted from 239 published studies. Each earthquake is associated with a list of studies providing relevant parameters needed for its comprehensive description from a seismological point of view, primarily epicentral position and magnitude. The archive is a source of information of extraordinary importance since it makes the procedure adopted for the construction of the historical catalogue completely transparent and reproducible, and it ensures its future expandability by benefitting from the knowledge already gathered.

The GHEC (version 1.0) catalogue contains 825 events of magnitude 7.0 and larger; this magnitude threshold had been lowered in stable continental regions in order to incorporate important earthquakes that otherwise would have been neglected. The global historical catalogue was compiled by taking for each event in the GHEA archive the parameters provided by the preferred study selected considering the quality of the information used for the description of the earthquake and the methodology adopted for the determination of the earthquake parameters.

Figure 2 shows the geographic distribution of the events included in the catalogue. In the period between 1000 and 1490 the catalogue contains only events in Europe, the Middle East, China and Japan, whilst from the end of the 16th century the catalogue contains also earthquakes occurring in the Americas.

Estimates of earthquake parameters in historical catalogues are habitually affected by epistemic uncertainties that can be explained by the paucity of the information available and the relevant subjective component involved in the process - which is indispensable for a comprehensive interpretation of the original information. In the construction of the GEH catalogue, despite only a limited number of studies provided this information, special treatment was devoted to the characterization of uncertainty related to location and magnitude. Albini et al. [2014a] explain that the majority of the earthquakes included in the catalogue are affected by an error in the estimation of the magnitude in the order of half a unit; according to the same authors only for a limited number of events this error exceeds one unit of

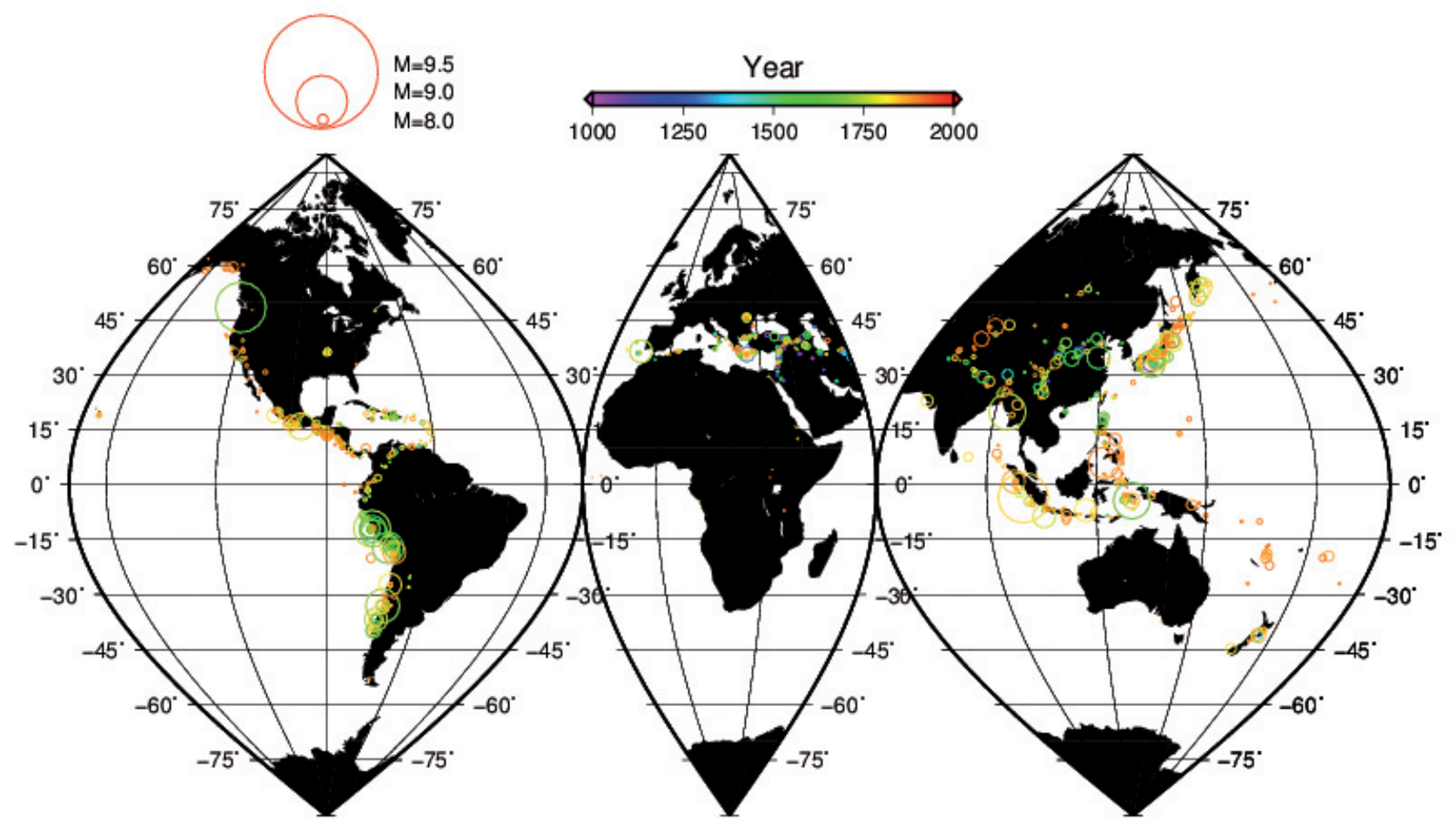

Figure 2. Geographic distribution of the epicenters included in the GEH catalogue [Albini et al. 2014a]. The color indicates the year of occurrence. 


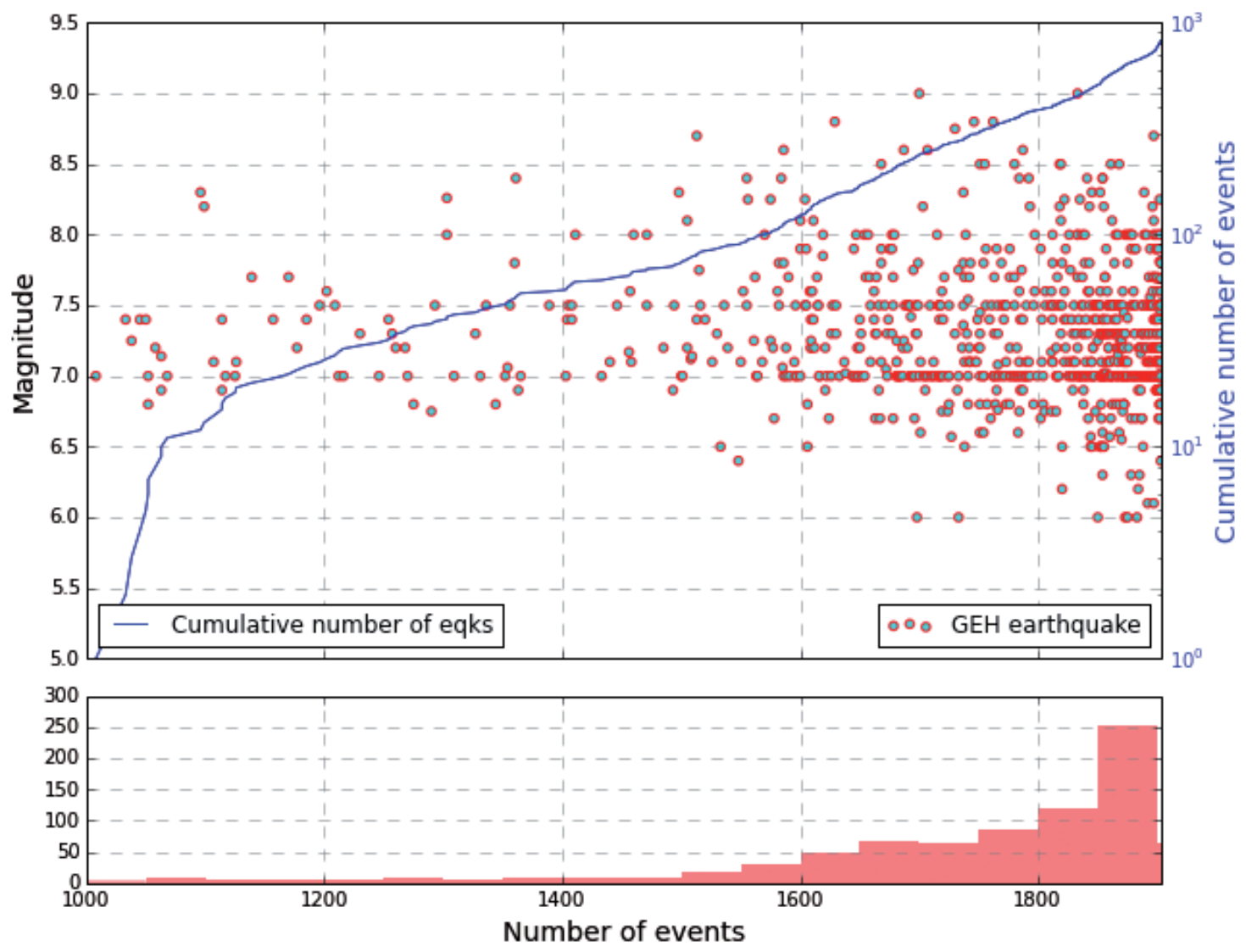

Figure 3. Time-magnitude space plotting of the earthquakes included in the GEH catalogue.

magnitude. In Figure 3 we depict the distribution in the time-magnitude space of the earthquakes included in the GEH catalogue as well as their cumulative curve with respect to time.

\subsection{Global strain rate model}

The contribution of remote sensing to the comprehension of the geodynamic processes increased exponentially over the last few years thanks to large technological improvements and the spread of more advanced instrumentation [Tralli et al. 2005].

Recognizing the importance of results deriving from the modeling of remotely sensed information, GEM promoted a project, called the GEM Global Strain Rate Model (GSRM2), which leveraged from the results of the Global Strain Rate Model project (http:/ / gsrm.un avco.org/intro/, Kreemer et al. [2003]). The project involved scientists from the University of Nevada, the University of California at Los Angeles, the China Earthquake Administration and UNAVCO.

The goal of the GSRM2 was the creation of a model describing the secular deformation on a $0.2^{\circ} \times 0.25^{\circ}$ mesh covering the deforming areas of the world. A considerable portion of the project activities was devoted to the creation and processing of an extensive database of global positioning system (GPS) velocity observations, which ideally should cover homogenously the en- tire globe. The GSRM2 project used 22,415 velocities at about 18,300 locations; 17,567 velocities characterize deforming areas while the remaining part have been measured on rigid plates.

The calculation of strain on this mesh was completed using the methodology proposed by Haines and Holt [1993] which computes the strain field - as well as vortices and expected velocities - through an interpolation methodology based on splines.

Figure 4 shows the spatial distribution of the second invariant of the strain tensor as defined in the most recent release of the GEM Global Strain rate model.

Bird et al. [2015] used the GEM Global Strain rate model for the construction of a hybrid earthquake forecast model, which combines the rates obtained by smoothing the seismicity within an instrumental catalogue with the ones obtained by applying the SHIFT methodology (Seismic Hazard Inferred From Tectonics; Bird and Liu [2007]) to the results of GSRM2.

Sevilgen et al. [2014] utilize the global strain rate model to infer the activity rates of active faults within some countries in the Balkans region. The comparison between the rates obtained using this new technique and the ones defined by earthquake geologists based on expert judgment overall show a good agreement. The overall goal in this case is to build a PSHA input model combining faults and distributed seismicity sources. 


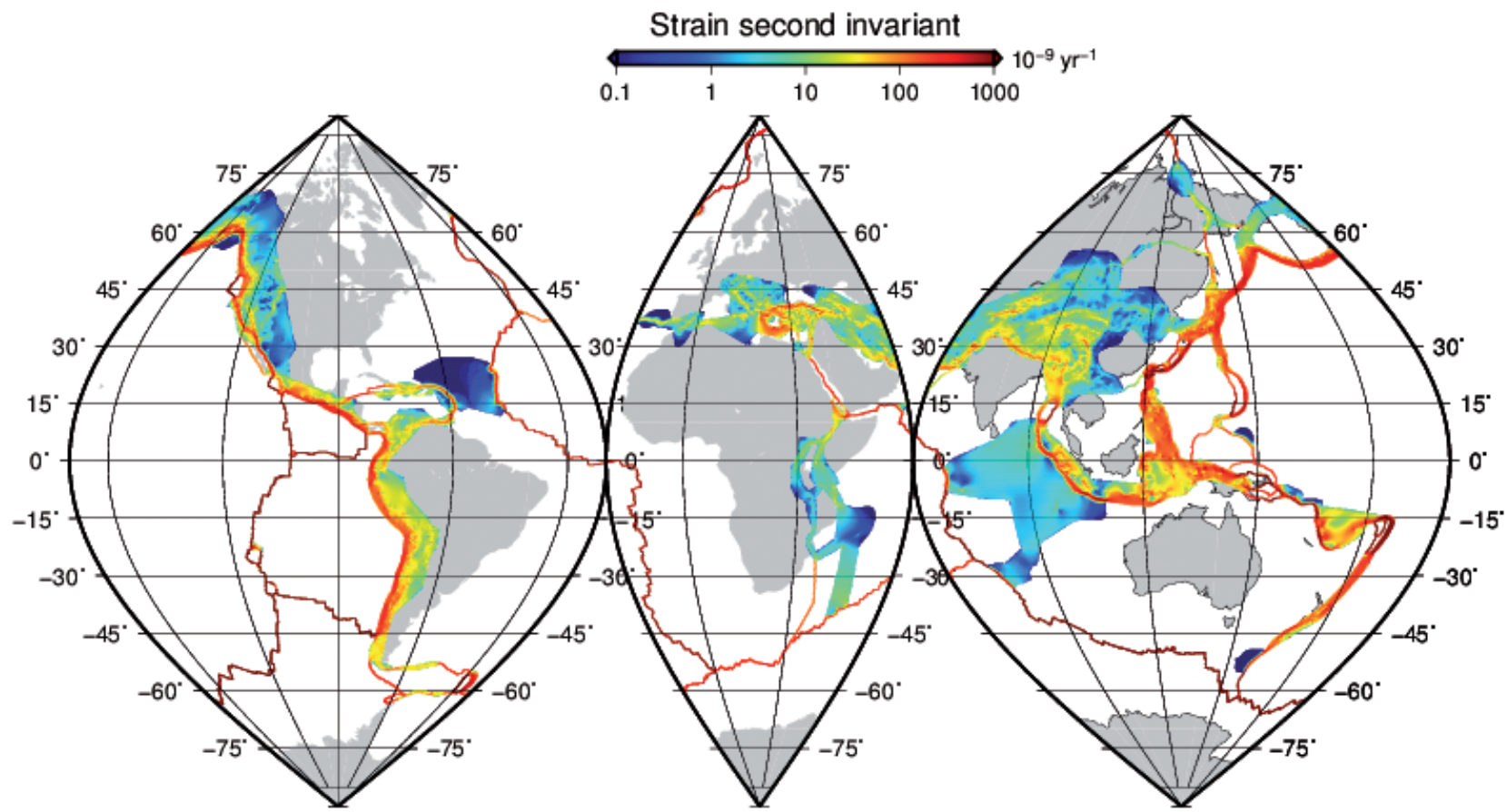

Figure 4. Geographic distribution of the second invariant of the strain tensor as defined in the version 2.1 of the GEM Global Strain Rate model [Kreemer et al. 2014a, 2014b].

\subsection{Active fault database}

Earthquake geology is a critical source of information for the creation of state-of-the-art probabilistic seismic hazard input models. Nevertheless, the manner by which geologically based information is assimilated into the construction of seismicity occurrence models for individual fault structures, as well as for actively deforming tectonic regions, is still the subject of scientific research [e.g. Field and Page 2011].

Recognizing the importance of this discipline and the significance of improving and harmonizing the description and modelling of fault sources, GEM sponsored a project - named "Faulted Earth" (FE) - which worked on the creation of a database of active faults with global coverage. GNS Science (New Zealand) led this project, which involved experts from almost all the continents.

The initial part of the project was predominantly focused on the construction of a database with a structure capable to incorporate information currently included in the most important national active fault databases publicly available. The information in the GEM active fault database is divided into a number of levels organized hierarchically, ranging from punctual data collected on the field until the description of segments structure and the illustration of a fault source as it used in PSHA analysis. Figure 5 shows an example for Japan of the collection of active fault sections included in the GFE database.

The second phase focused on populating this database with information included in the most recent and advanced databases of active faults available. The databases of active fault incorporated into the GEM Faulted Earth (GFE) database are the following ones:

- The New Zealand active fault database (Jongens and Dellow [2003]; http: / / data.gns.cri.nz. / af, last accessed on September 2014).

- The active fault database of Japan (https: / / gbank. gsj.jp/activefault/index_e_gmap.html, last accessed on September 2014).

- The quaternary fault and fold database of the United States (Machette et al. [2004]; http: / / earthquake. usgs.gov/hazards/qfaults/, last accessed September 2014).

- The Australian neo-tectonic feature database (Clark et al. [2011]; http: / / www.ga.gov.au/ earthquakes/ static PageController.do?page $=$ neotectonics, last accessed September 2014).

- The Alaska quaternary fault and folds database (Koehler et al. [2012]; http: / / www.dggs.alaska.gov/ pubs/id/23944, last accessed on September 2014).

The Faulted Earth project also developed, in collaboration with the Science and Technology teams at the GEM Secretariat, a web based tool for the compilation of information describing active faults from punctual data collected in the field to fault descriptions that can be readily ported into an hazard input model.

The GEM Faulted Earth project promoted also a number of auxiliary initiatives aimed at creating a comprehensive framework for the incorporation of faults into hazard models. A special task group worked on the creation of a global database of subduction inter- 
face sources [Berryman et al. 2014] while a second one worked at appraising the available magnitude scaling relationships available for different tectonic contexts [Stirling et al. 2013].

\subsection{Global ground motion prediction equations}

The Pacific Earthquake Engineering Research Center (PEER) coordinated the "Global GMPEs" (GGMPEs) project, a project that had the primary goal of selecting a suite of Ground Motion Prediction Equations (GMPEs) to be used for hazard calculation at global scale. A secondary, though not less important, objective of this project was to define a framework for the selection of GMPEs for hazard analysis in different tectonic contexts and regions of the world. While the first goal has clearly a more immediate application - given the high number of new GMPEs published every year - the second goal provides ways to maintain the suite of GMPEs updated.

The GGMPEs project was organized into six tasks:

1. Definition of a consistent strategy of modelling ground motion: (a) Consistency in model parameters; (b) Consistency in site parameters.

2. Compilation and critical review of GMPEs.

3. Selection or derivation of a global set of GMPEs.
4. Inclusion of near-fault effects.

5. Database of Recorded Waveforms.

6. Specifications for compilation of a global database of Soil Classification.

The first task provided guidance on the most suitable predictor variables to be used for the construction of empirical ground motion prediction equations (e.g. magnitude type, magnitude range commonly covered, rupture-site distances), as well as on the intensity measure types that should be used for representing the intensity of the shaking.

The second task leveraged from the extensive review of the literature related to ground motion prediction equations, continuing the extensive archiving of GMPEs initiated by Douglas [2001] and updated in Douglas [2011a]. Starting from this large collection of models, and in order to obtain a doable number of models, the pre-selection criteria proposed by Cotton et al. [2006] had been applied in a manner as to balance the need to cover, to the largest extent possible, the epistemic uncertainty within the smallest set of potential GMPEs to be analysed within task 3 .

Task 3 focused [Stewart et al. 2013, 2015] on defining a general transparent strategy for the selection of ground motion prediction equations which is based on:

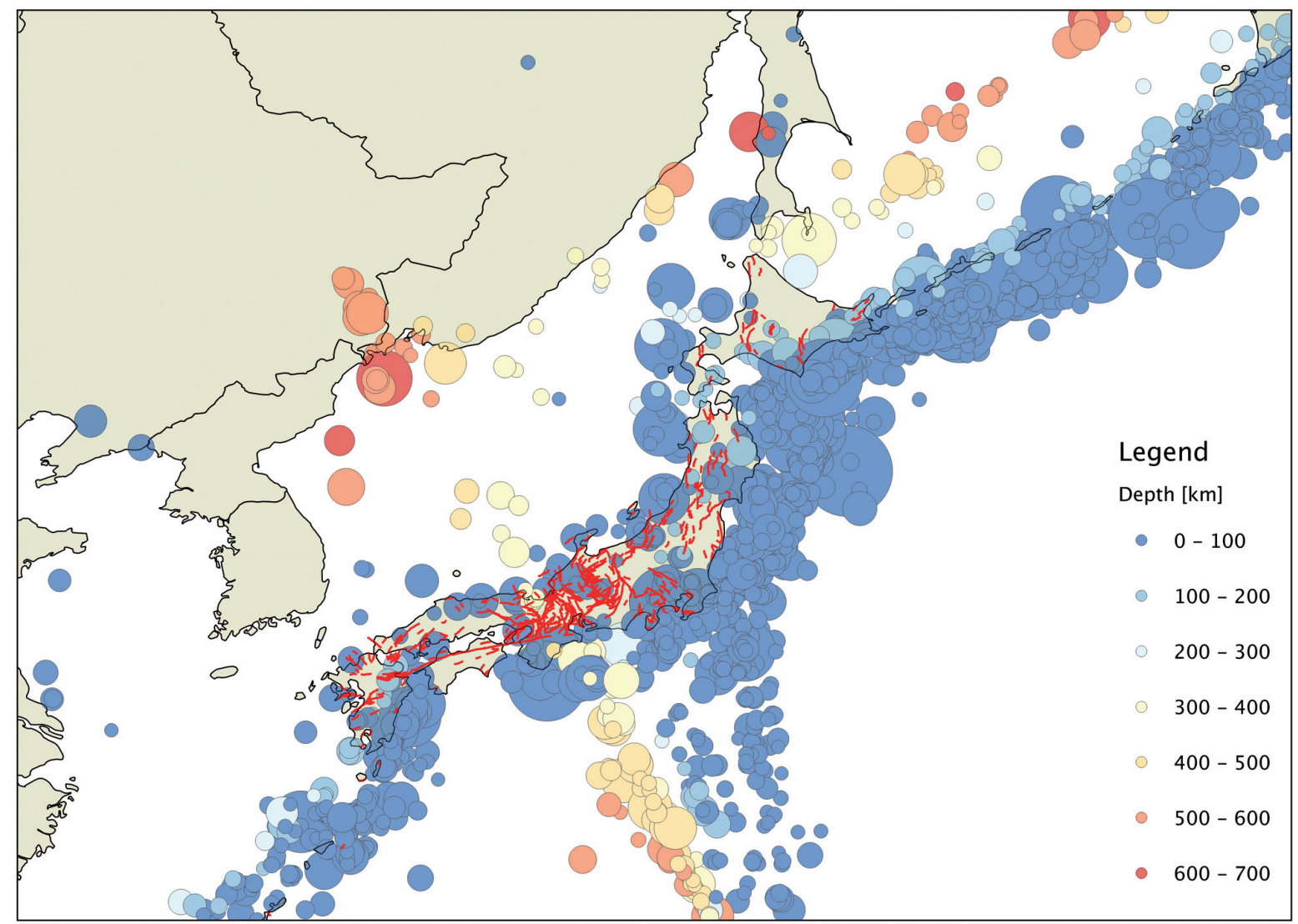

Figure 5. Example of fault section traces included in the GEM Faulted Earth database. Earthquake epicenters belong to the ISC-GEM catalogue [Storchak et al. 2013]; the radius of the circles used to represent the epicenters is proportional to the rupture length while the face color indicates the hypocentral depth as explained in the legend. 
PAGANI ET AL.

Subduction sources

\begin{tabular}{|c|c|c|}
\hline Abrahamson et al. [2015] & \multicolumn{2}{|l|}{ AEA12 } \\
\hline Atkinson and Boore [2003] & \multicolumn{2}{|l|}{ AB03 } \\
\hline Zhao et al. [2006] & \multicolumn{2}{|l|}{ ZEA12 } \\
\hline \multicolumn{3}{|c|}{ Stable continental regions } \\
\hline \multicolumn{3}{|l|}{ Pezeshk et al. [2011] } \\
\hline Atkinson and Boore [2006] & $\mathrm{AB} 06^{\prime}$ & $\begin{array}{l}\text { This model includes the updated } \\
\text { proposed by Atkinson and Boore [2011]. }\end{array}$ \\
\hline Silva et al. [2002] & SEA02 & $\begin{array}{l}\text { Aleatory variability (i.e. standard deviation) } \\
\text { model replaced by the one of EPRI [1993]. }\end{array}$ \\
\hline \multirow[t]{2}{*}{ Toro et al. [1997] } & TEA97' & $\begin{array}{l}\text { This model includes the updated } \\
\text { proposed by Toro [2002]. }\end{array}$ \\
\hline & \multicolumn{2}{|c|}{ Active crustal regions } \\
\hline Akkar and Bommer [2010] & \multicolumn{2}{|l|}{$\mathrm{AB} 10$} \\
\hline Chiou and Youngs [2008] & \multicolumn{2}{|l|}{ CY08 } \\
\hline Zhao et al. [2006] & \multicolumn{2}{|l|}{ ZEA06 } \\
\hline
\end{tabular}

Table 1. Ground motion prediction equations selected by the Global GMPEs project for the calculation of seismic hazard at a global scale [Stewart et al. 2013, 2015].

- The study of the predicted values of ground motions in a multidimensional space composed by the most important predictor variables (e.g. magnitude, rupture-site distance etc.);

- The analysis of the functional form;

- The completion of several quantitative tests assessing the level of agreement between the predicted values of shaking and the values observed.

The set of GMPEs selected is summarized in Table 1. The project highlighted issues related to GMPE selection in less well-constrained tectonic regions, such as volcanic areas, deep non-subduction areas (e.g. Vrancea) and areas affected by earthquakes with propagation paths within oceanic crust. Recognising the limitations of the current knowledge in such regions, however, the group refrained from providing a specific GMPE selection in those cases.

Stewart et al. [2013] suggest that nonlinear site amplification models should be preferred to the linear sitecorrection terms and provide guidance on how GMPEs should be modified in this sense.

Task 4 addressed the problem of incorporating near source effects into the modelling of ground motion while task 5 compiled a collection of strong ground motion databases. Finally, the last task of the project provided guidance for the construction of a database of soil information.

Campbell et al. [2013] combines the GMPEs included in the GEM Global Ground Motion Prediction Equation to create a ground motion models for loss es- timation in Australia based on the hazard model published by Geoscience Australia in 2012.

Haendel et al. [2015] uses the set of GMPEs preselected by Douglas [2011b] for the subduction environment to create a mixture models for an area in the northern of Chile. These authors prove that in the selected area the values of ground motion computed with mixture models when compared against observed data outperforms single GMPEs.

\section{Challenges in using GEM global datasets for seismic hazard assessment at regional and national scales}

In promoting global projects, GEM's principal aim had been the production of information supporting the development of new regional and national seismic hazard models. The results achieved by these projects are an unprecedented collection of information in terms of homogeneity, global coverage and overall quality.

In the following we discuss some recommendations and signal some critical aspects that in our opinion should be considered in creation of hazard source models and ground motion models based on the outcomes of the GEM hazard global components.

\subsection{Earthquake catalogues}

Within probabilistic seismic hazard analysis the processing of catalogues is still the primary information used for the characterization of distributed seismicity. However, the use of earthquake catalogues in regional and national seismic hazard assessments still 
presents at least two major issues: (1) the compilation of an homogenous catalogue starting from a set of non uniform catalogues and (2) the selection of the best algorithms (and the parameters needed for their use) for processing seismicity from the original seismicity catalogue until the calculation of the parameters characterizing the magnitude-frequency distribution.

Figure 6 shows a comparison between the SHARE and ISC-GEM catalogues for a rectangle covering part of southern Europe in a time-magnitude space. This plot emphasizes the necessity of complementing the ISCGEM catalogue with regional (and/ or national) databases since the ISC-GEM alone does not provide sufficient information to comprehensively characterize seismicity occurrence in the intermediate and low magnitude range.

The recent literature contains several interesting examples describing the creation of harmonized seismicity catalogues specifically created for seismic hazard analysis purposes. Beauval et al. [2013] for example describe the process adopted for the construction of a composite catalogue starting from the information included in a number of national, regional and international datasets. The procedure described shows a possible example of how GEM global catalogues can be combined with local catalogues for the construction of seismicity catalogue for hazard analysis.

The catalogue processing is usually the result of a sequence of different operations: declustering, com- pleteness analysis, magnitude-frequency distribution selection and calculation of the corresponding parameters via regression analysis. In this case, the recent literature contains few contributions discussing the impact on hazard results of the procedures adopted for the processing of seismicity. The documentation accompanying PSHA input models, seldom discusses the details of the procedure adopted to process the catalogue and to characterize the magnitude-frequency distribution. Christophersen et al. [2011] discusses the impact of different declustering methods on the final values of hazard and conclude that the choice of the algorithm has limited impact on high values of shaking (above $0.4 \mathrm{~g}$ ). The PSHA model used to complete this study is the 2010 New Zealand model [Stirling et al. 2012], which is a combination of faults and distributed seismicity sources, the latter modelled through grid sources created by smoothing seismicity. The hazard at low values of annual frequency of exceedance is most probably controlled by faults and this might justify the little impact of declustering observed for high values of hazard.

The GEM Hazard Modeller's Toolkit contains a large number of algorithms commonly adopted for the characterization of seismic sources based on earthquake catalogues. This suite of tools will hopefully help in making the PSHA input model preparation process more transparent and in understanding even further the impact of different algorithms on the final values of hazard.
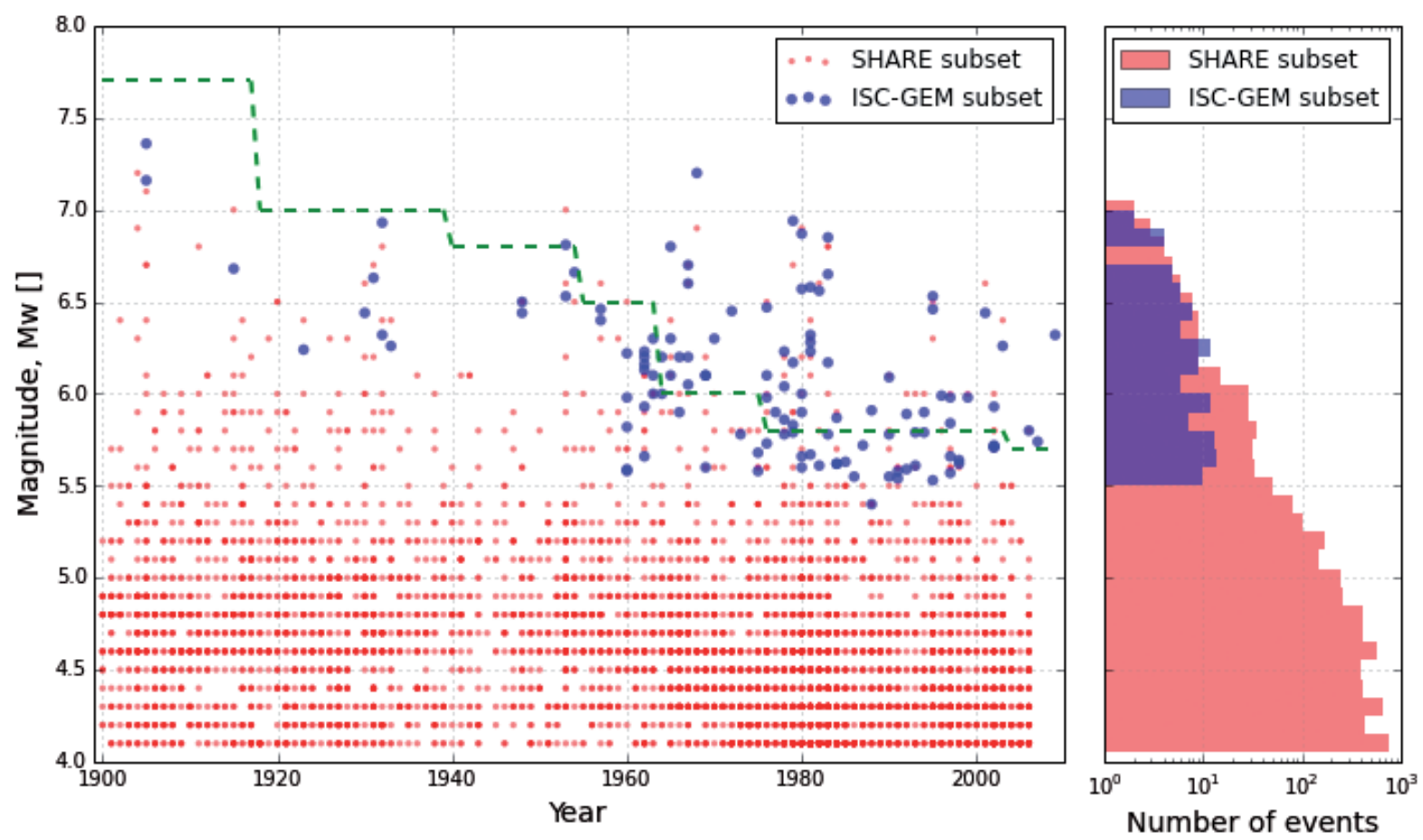

Figure 6. (Left panel) Time-Magnitude plot showing the earthquakes included in the ISC-GEM and SHARE catalogues. The earthquakes in this plot have magnitude larger than 4.0 and epicentral location included between longitude $0^{\circ}$ and $25^{\circ} \mathrm{E}$ and latitude comprised between $38^{\circ} \mathrm{N}$ and $55^{\circ} \mathrm{N}$. (Right panel) Histograms showing the distribution per magnitude bins ( 0.1 magnitude units width) of the two catalogues considered in this example. The green dashed line shows the completeness intervals proposed by Michael [2014]. 


\subsection{Active fault data}

State-of-practice seismic hazard models for active tectonic regions nowadays should include fault sources. However, the database of active fault produced by the GEM Faulted Earth initiative does not cover large parts of the world. The plan is to integrate the GFE database with the information produced within regional projects such as in the case of SHARE, EMME, EMCA and SARA. We also hope that people looking at the fault related information that will distributed publically through the OpenQuake-platform will feel more eager to share information and therefore improve the overall spatial coverage of the GEM databases.

From a methodological perspective, one of the major issues related with the incorporation of faults sources into regional PSHA models pertains to the correct treatment of epistemic uncertainty and the inherent calculation complexity. Information about faults can be collected using different methodologies [e.g. McCalpin 2009], though a majority of cases the basic information coming from observation is punctual i.e. it refers to a specific observation point of an active fault structure, therefore an effort in reconciling these observations in order to define an overall description of fault characteristics is generally asked to the earthquake geologist. The large epistemic uncertainties connected with this process and the necessity to formally account for epistemic uncertainties in the PSHA model building process indicate the importance of a strong interaction between experts of different disciplines and particularly between earthquake geologists and hazard modelers.

\subsection{Strain rate}

The use of strain modeling for probabilistic seismic hazard analysis is still a research topic. The scientific literature contains only few examples discussing the incorporation of strain in the construction of the PSHA seismic source model. Mazzotti et al. [2011] use a logic tree methodology to incorporate seismicity rates inferred from a statistical analysis of catalogues with the ones obtained from strain using the classic Kostrov [1974] formula.

Extensive research on the best approaches having the capacity to incorporate geodetic surface deformation information into a seismicity occurrence model had been performed in the framework of the UCERF projects (Uniform California Earthquake Rupture Forecast; Field et al. [2009, 2014]). In UCERF2 for example the slip rate on some faults as well as the rates for type-C sources were constrained using strain values derived from geodesy.

Bird and Liu [2007] proposed a methodology providing long-term seismicity forecasts using a kine- matic model describing the recent tectonic process, the methodology used by Bird et al. [2015] to compute a global earthquake forecast model. A forecast model is a first very important step toward the creation of a regional hazard model but technical speaking is not PSHA Seismic Source model (Weatherill and Pagani [2014] briefly discusses the differences between a forecast model and a hazard model). The SHIFT methodology can be adapted to obtain the information needed for the creation of a hazard model and, according to authors' opinion, it offers the most viable option for incorporating strain into PSHA regional models.

\subsection{Ground motion prediction equations}

The GGMPE project completed a comprehensive study and provided an initially recommended set of GMPEs. Recognizing the need to keep this set of GMPEs updated with time they also suggested a methodology to be adopted for the selection of GMPEs. The GEM Ground Motion toolkit comprises most of the tools needed to implement the recommendations of Stewart et al. [2015].

\section{Conclusions}

We summarized the main achievements of the five global projects supported by the Global Earthquake Model initiative during the first implementation phase (2009-2014) and we briefly discussed examples of applications as well as challenges in incorporating their results into new seismic hazard models.

Most of the datasets and guidelines produced by these projects constitute an improvement of our knowledge of the earthquake process and particularly of the most relevant components of regional probabilistic seismic hazard input models. The challenge is now to identify the missing gaps and promote mechanisms that will help maintaining these products updated and improved.

The GEM datasets currently do not contain information on site conditions, this is a gap that GEM aims to incrementally fill in the second implementation phase mostly though accumulation of open knowledge that will be collected and produced by new projects we will be carrying out in different parts of the world. GEM does not envision sponsoring for the second implementation phase projects similar to the ones described in this paper. Cooperation with the scientific community remains nevertheless a primary goal of GEM; the ambition is to do it though a large and diffuse number of projects.

\section{References}

Abrahamson, N.A., N. Gregor and K. Addo (2015). BC Hydro Ground Motion Prediction Equations for Subduction Earthquakes, Earthq. Spectra, in press; 
doi:http:/ / dx.doi.org/10.1193/051712EQS188MR. Akkar S., and J.J. Bommer (2010). Empirical equations for the prediction of PGA, PGV and spectral accelerations in Europe, the Mediterranean region and the Middle East, Seismol. Res. Lett., 81 (2), 195-206.

Albini, P., R.M.W. Musson, A.A. Gomez Capera, M. Locati, A. Rovida, M. Stucchi and D. Viganò (2014a). Global Historical Earthquake Archive and Catalogue (1000-1903), GEM Technical Report 2013-01 V1.0.0, GEM Foundation, Pavia, Italy, 202 pp.; doi:10.13117/GEM.GEGD.TR2013.01.

Albini, P., R.M.W. Musson, A. Rovida, M. Locati, A.A. Gomez Capera and D. Viganò (2014b). The Global Earthquake History, Earthq. Spectra, 30 (2), 607-624; doi:http:/ / dx.doi.org/10.1193/122013EQS297.

Atkinson, G.M., and D.M. Boore (2003). Empirical ground-motion relations for subduction zone earthquakes and their application to Cascadia and other regions, B. Seismol. Soc. Am., 93 (4), 1703-1729.

Atkinson, G.M., and D.M. Boore (2006). Earthquake ground-motion prediction equations for eastern North America, B. Seismol. Soc. Am., 96 (6), 21812205.

Atkinson, G.M., and D.M. Boore (2011). Modifications to existing ground-motion prediction equations in light of new data, B. Seismol. Soc. Am., 101 (3), 1121-1135.

Beauval, C., H. Yepes, P. Palacios, M. Segovia, A. Alvarado, Y. Font, J. Aguilar, L. Troncoso and S. Vaca (2013). An Earthquake Catalog for Seismic Hazard Assessment in Ecuador, B. Seismol. Soc. Am., 103 (2A), 773-786; doi:10.1785/0120120270.

Berryman, K., L. Wallace, G. Hayes, P. Bird, K. Wang, R. Basili, T. Lay, M. Pagani, R. Stein, T. Sagiya, C. Rubin, S. Barreintos, C. Kreemer, N. Litchfield, M. Stirling, K. Gledhill, K. Haller and C. Costa (2014). The GEM Faulted Earth Subduction Characterisation Project. Version 1.0, June 2014, GEM Faulted Earth Project; available at http: / / www.nexus.glob alquakemodel.org/gem-faulted-earth/posts.

Bird, P., and Z. Liu (2007). Seismic hazard inferred from tectonics: California, Seismol. Res. Lett., 78 (1), 37-48.

Bird, P., D.D. Jackson, Y.Y. Kagan, C. Kreemer and R.S. Stein (2015). GEAR1: a Global Earthquake Activity Rate model constructed from geodetic strain rates and smoothed seismicity, B. Seismol. Soc. Am., submitted.

Bondar, I., and D. Storchak (2011). Improved location procedures at the International Seismological Centre, Geophys. J. Int., 186, 1220-1244; doi:10.1111/j. 1365-246X.2011.05107.x.

Campbell, K.W., P.C. Thenhaus, N. Gupta, D.F. Smith and M.M. Khater (2013). Earthquake hazard model for loss estimation in Australia using the 2012 GA hazard data, In: Proceedings of the 2013 NZSEE Conference, paper no. 6.

Chiou, B.S.J., and R.R. Youngs (2008). An NGA model for the average horizontal component of peak ground motion and response spectra, Earthq. Spectra, 24 (1), 173-215.

Christophersen, A., M.C. Gerstenberger, D.A. Rhoades and M.W. Stirling (2011). Quantifying the effect of declustering on probabilistic seismic hazard, In: Proceedings of the Ninth Pacific Conference on Earthquake Engineering, paper no. 206.

Christophersen, A., D.A. Rhoades, S. Hainzl, E.G.C. Smith and M.C. Gerstenberger (2013). The Canterbury sequence in the context of global earthquake statistics, GNS Science Consultancy Report 2013/ 196.

Clark, D., A. McPherson and C.D.N. Collins (2011). Australia's seismogenic neotectonic record: a case for heterogeneous intraplate deformation. Geoscience Australia Record 2011/11, 95 pp.

Cotton, F., F. Scherbaum, J.J. Bommer and H. Bungum (2006). Criteria for selecting and adjusting groundmotion models for specific target regions: Application to Central Europe and rock sites, J. Seismol., 10, 137-156.

Crowley, H., R. Pinho, M. Pagani and N. Keller (2013). Assessing global earthquake risks: the Global Earthquake Model (GEM) initiative, In: K.S. Tesfamariam and K. Goda (eds.), Handbook of Seismic Risk Analysis and Management of Civil Infrastructure Systems, Woodhead Publishing, 815-838; doi:10.15 33/9780857098986.5.815.

Danciu, L., and D. Giardini (2015). Global Seismic Hazard Assessment Program - GSHAP legacy, Annals of Geophysics, 58 (1), S0109; doi:10.4401/ag-6734.

Di Giacomo, D., I. Bondar, D.A. Storchak, E.R. Engdahl, P. Bormann and J. Harris (2014). ISC-GEM: Global Instrumental Earthquake Catalogue (19002009), III. Re-computed MS and mb, proxy MW, final magnitude composition and completeness assessment, Phys. Earth Planet. In.; http:/ / dx.doi.org/ 10.1016/j.pepi.2014.06.005.

Douglas, J. (2001). A comprehensive worldwide summary of strong-motion attenuation relationships for peak ground acceleration and spectral ordinates (1969 to 2000), Imperial College of Science and Technology, ESEE Report No. 01-1, January 2001.

Douglas, J. (2011a). Ground motion prediction equations 1964-2010, Final report, BRGM/RP-59356-FR, February 2011, 446 pp.

Douglas, J. (2011b). Ground Motion Prediction Equations 1964-2010, Rpt PEER 2011/102, Pacific Earthquake Engineering Research Center, University of 
California, Berkeley, CA.

Ekström, G., M. Nettles, and A.M. Dziewonski (2012). The global CMT project 2004-2010: centroid-moment tensors for 13,017 earthquakes, Phys. Earth Planet. In., 200/201, 1-9.

Engdahl, E.R., R. van der Hilst and R. Buland (1998). Global teleseismic earthquake relocation with improved travel times and procedures for depth determination, B. Seismol. Soc. Am., 88, 722-743.

Engdahl, E.R., and A. Villaseñor (2002). Global Seismicity: 1900-1999, In: W.H.K. Lee, H. Kanamori, P.C. Jennings and C. Kisslinger (eds.), International Handbook of Earthquake and Engineering Seismology, Academic Press, vol. 81A, § 41, 665-690.

EPRI, Electric Power Research Institute (1993). Guidelines for Determining Design Basis Ground Motions, vols. 1-5, EPRI TR-102293, EPRI, Palo Alto, CA.

Field, E.H., T.E. Dawson, K.R. Felzer, A.D. Frankel, V. Gupta, T.H. Jordan, T. Parsons, M.D. Petersen, R.S. Stein, R.J. Weldon II and C.J. Wills (2009). Uniform California Earthquake Rupture Forecast, version 2 (UCERF 2), B. Seismol. Soc. Am., 99, 2053-2107; doi:10.1785/0120080049.

Field, E.H., and M.T. Page (2011). Estimating Earthquake-Rupture Rates on a Fault or Fault System, B. Seismol. Soc. Am., 101 (1), 79-92; doi:10.1785/01201 00004.

Field, E.H., R.J. Arrowsmith, G.P. Biasi, P. Bird, T.E. Dawson, K.R. Felzer, D.D. Jackson, K.M. Johnson, T.H. Jordan, C. Madden, A.J. Michael, K.R. Milner, M.T. Page, T. Parsons, P.M. Powers, B.E. Shaw, W. R. Thatcher, R.J. Weldon II and Y. Zeng (2014). Uniform California earthquake rupture forecast, version 3 (UCERF3) - The time-independent model, B. Seismol. Soc. Am., 104, 1122-1180; doi:10.1785/ 0120 130164.

Giardini, D., G. Grünthal, K.M. Shedlock and P. Zhang (1999). The GSHAP Global Seismic Hazard Map, Annali di Geofisica, 42 (6), 1225-1230; doi:10.4401/ ag-3784.

Giardini, D., J. Woessner and L. Danciu (2014). Mapping Europe’s Seismic Hazard, EOS, 95 (29), 261262.

Geist, E.L. (2014). Explanation of Temporal Clustering of Tsunami Sources Using the Epidemic-Type Aftershock Sequence Model, B. Seismol. Soc. Am., 104 (4), 2091-2103; doi:10.1785/0120130275.

Guidoboni, E. (2002). Historical Seismology: the Long Memory of the Inhabited World; In: W.H.K. Lee, H. Kanamori, P.C. Jennings and C. Kisslinger (eds.), International Handbook of Earthquake and Engineering Seismology, Academic Press, vol. 81A, $\S 47$, 775-791.
Haendel, A., S. Specht, N.M. Kuehn and F. Scherbaum (2015). Mixtures of ground-motion prediction equations as backbone models for a logic tree: an application to the subduction zone in Northern Chile, B. Earthq. Eng., 13, 483-501; doi:10.1007/s10518-0149636-7.

Haines, A.J., and W.E. Holt (1993). A procedure for obtaining the complete horizontal motions within zones of distributed deformation from the inversion of strain rate data, J. Geophys. Res., 98 (B7), 1205712082; doi:10.1029/93JB00892.

Hayes, G.P., D.E. McNamara, L. Seidman and J. Roger (2013). Quantifying potential earthquake and tsunami hazard in the Lesser Antilles subduction zone of the Caribbean Region, Geophys. J. Int., 195, 510-521; doi:10.1093/ gji/ggt385.

Jongens, R., and G. Dellow (2003). The active faults database of New Zealand: Data dictionary, Institute of Geological \& Nuclear Sciences science report, $2003 / 17$.

Koehler, R.D., R.-E. Farrell, P.A.C. Burns and R.A. Combellick (2012). Quaternary faults and folds in Alaska: A digital database, Alaska Division of Geological \& Geophysical Surveys Miscellaneous Publication, 141.

Kostrov, V.V. (1974). Seismic moment and energy of earthquakes, and seismic flow of rocks, Izv. Acad. Sci. SSR Phys. Solid Earth, 1, 23-40.

Kreemer, C., W.E. Holt and A.J. Haines (2003). An integrated global model of present-day plate motions and plate boundary deformation, Geophys. J. Int., 154, 8-34.

Kreemer, C., G.E. Klein, Z.-K. Shen, M. Wang, L. Estey, S. Wier and F. Boler (2014a). Global Geodetic Strain Rate Model. GEM technical Report, 2014G07 V1.0.0, GEM Foundation, Pavia, Italy, 129 pp.; doi:10.13117/ GEM.GEGD.TR2014.07.

Kreemer, C., G. Blewitt and E.C. Klein (2014b). A geodetic plate motion Global Strain Rate Model, Geochem. Geophys. Geosyst., 15, 3849-3889; http: / / dx.doi.org/10.1002/2014GC005407.

Lee, W.H.K., and E.R. Engdahl (2015). Bibliographical search for reliable seismic moments of large earthquakes during 1900-1979 to compute $\mathrm{M}_{\mathrm{W}}$ in the ISCGEM Global Instrumental Reference Earthquake Catalogue, Phys. Earth Planet. In., 239, 25-32; http: / / dx.doi.org/10.1016/ j.pepi.2014.06.004.

Machette, M., K. Haller and L. Wald (2004). Quaternary Fault and Fold Database for the Nation, United States Geological Survey Fact Sheet, 2004-3033.

Mazzotti, S., L.J. Leonard, J.F. Cassidy, G.C. Rogers and S. Halchuk (2011). Seismic hazard in western Canada from GPS strain rates versus earthquake catalog, J. 
Geophys. Res., 116 (B12); doi:10.1029/2011JB008213, ISSN 0148-0227.

McCalpin, J., ed. (2009). Paleoseismology, International Geophysics Series, Academic Press, vol. 95.

Michael, A.J. (2014). How Complete is the ISC-GEM Global Earthquake Catalog?, B. Seismol. Soc. Am., 104, 1829-1837; doi:10.1785/0120130227.

Pagani, M, D. Monelli, G. Weatherill, L. Danciu, H. Crowley, V. Silva, P. Henshaw, L. Butler, M. Nastasi, L. Panzeri, M. Simionato and D. Vigano (2014). OpenQuake-engine: An Open Hazard (and Risk) Software for the Global Earthquake Model, Seismol. Res. Lett., 85 (3), 692-702; doi:10.1785/ 0220130087.

Parolai, S., J. Zschau and U. Begaliev (2015). Preface, Annals of Geophysics, 58 (1): Special issue "Earthquake Model Central Asia: seismic hazard and risk assessment in Central Asia”, S0101; doi:10.4401/ag6784.

Pezeshk, S., A. Zandieh and B. Tavakoli (2011). Hybrid empirical ground-motion prediction equations for eastern North America using NGA models and updated seismological parameters, B. Seismol. Soc. Am., 101 (4), 1859-1870.

Pollitz, F., R. Stein, V. Sevilgen and R. Burgmann (2014). The Profound Reach of the 11 April 2012 M 8.6 Indian Ocean Earthquake: Short-Term Global Triggering Followed by a Longer-Term Global Shadow, B. Seismol. Soc. Am., 104, 972-984; doi:10.1785/ 012 0130078.

Scherbaum, F., E. Delavaud and C. Riggelsen (2009). Model selection in seismic hazard analysis: An information-theoretic perspective, B. Seismol. Soc. Am., 99 (6), 3234-3247.

Sesetyan, K., L. Danciu, M.B. Demircioglu, M. Erdik and D. Giardini (2014). EMME-HAZ-2014: Seismic Hazard Assessment results for the Middle East Region (abstract), In: Proceedings of the 2nd European Conference on Earthquake Engineering and Seismology (Istanbul, August 25-29, 2014).

Sevilgen, V., R.A. Bennett, I. Brlek, L. Danciu, V. Kastelic, S. Kovacevic, C. Kreemer, K. Kuk, N. Kuka, Z. Milutinovic, S. Mustafa, B. Sket-Motnikar, R.S. Stein and L. Vucic (2014). Balkans-OQ: a collaborative seismic hazard assessment of the Balkan countries using the OpenQuake software and the GEM strain rate model, In: Proceedings of the 2nd European Conference on Earthquake Engineering and Seismology (Istanbul, August 25-29, 2014).

Silva, W.J., N. Gregor and R. Darragh (2002). Development of regional hard rock attenuation relations for central and eastern North America, Report from Pacific Engineering and Analysis, El Cerrito, California, $57 \mathrm{pp}$.
Stewart, J.P., J. Douglas, M.B. Javanbarg, C. Di Alessandro, Y. Bozorgnia, N.A. Abrahamson, D.M. Boore, K.W. Campbell, E. Delavaud, M. Erdik and P. Stafford (2013). GEM-PEER Task 3 Project: Selection of a Global Set of Ground Motion Prediction Equations, PEER Report 2013/22, December 2013, 251 pp.

Stewart, J.P., J. Douglas, M. Javanbarg, Y. Bozorgnia, N.A. Abrahamson, D.M. Boore, K.W. Campbell, E. Delavaud, M. Erdik and P.J. Stafford (2015). Selection of Ground Motion Prediction Equations for the Global Earthquake Model, Earthq. Spectra, 31 (1), 1945; doi:http:/ / dx.doi.org/10.1193/013013EQS017M.

Stirling, M., G. McVerry, M. Gerstenberger, N. Litchfield, R. Van Dissen, K. Berryman, P. Barnes, L. Wallace, P. Villamor, R. Langridge, G. Lamarche, S. Nodder, M. Reyners, B. Bradley, D. Rhoades, W. Smith, A. Nicol, J. Pettinga, K. Clark and K. Jacobs (2012). National Seismic Hazard Model for New Zealand: 2010 Update, B. Seismol. Soc. Am., 102 (4), 1514-1542.

Stirling, M., T. Goded, K. Berryman and N. Litchfield (2013). Selection of Earthquake Scaling Relationships for Seismic-Hazard Analysis, B. Seismol. Soc. Am., 106 (3), 1-19; doi:10.1785/0120130052.

Storchak, D.A., D. Di Giacomo, I. Bondár, J. Harris, E.R. Engdahl, W.H.K. Lee, A. Villaseñor, P. Bormann and G. Ferrari (2012). ISC-GEM Global Instrumental Earthquake Catalogue (1900-2009), GEM Technical Report 2012-01 V1.0.0, GEM Foundation, Pavia, Italy, 128 pp.; doi:10.13117/GEM.GEGD.TR 2012.01.

Storchak, D., D. Di Giacomo, I. Bondar, E.R. Engdahl, J. Harris, W.H.K. Lee, A. Villasenor and P. Bormann (2013). Public Release of the ISC-GEM Global Instrumental Earthquake Catalogue (1900-2009), Seismol. Res. Lett., 84 (5), 810-815; doi:10.1785/ 022013 0034.

Storchak, D.A., D. Di Giacomo, E.R. Engdahl, J. Harris, I. Bondár, W.H.K. Lee, P. Bormann and A. Villaseñor (2015). The ISC-GEM Global Instrumental Earthquake Catalogue (1900-2009): Introduction, Phys. Earth Planet. In., 239, 48-63; ISSN 0031-9201, http:// dx.doi.org/10.1016/j.pepi.2014.06.009.

Toro, G.R., N.A. Abrahamson and J.F. Schneider (1997). Model of strong ground motions from earthquake in central and eastern North America: Best estimates and uncertainties, Seismol. Res. Lett., 68 (1), 41-57.

Toro, G.R. (2002). Modification of the Toro et al. (1997) Attenuation Equations for Large Magnitudes and Short Distances, Technical Report, Risk Engineering, Inc., Louisville, CO; available at http: / / www. riskeng.com/downloads/attenuation_equations. 
Tralli, D.M., R.G. Blom, V. Zlotnicki, A. Donnellan and D.L. Evans (2005). Satellite remote sensing of earthquake, volcano, flood, landslide and coastal inundation hazards, ISPRS Journal of Photogrammetry $\&$ Remote Sensing, 59, 185-198.

Weatherill, G.A., M. Pagani and D. Monelli (2012). The Hazard Component of the GEM Modeller's Toolkit: A Framework for the Preparation and Analysis of Probabilistic Seismic Hazard (PSHA) Input Tools, In: Proceedings of the 15th World Conference on Earthquake Engineering, Lisbon.

Weatherill, G.A., and M. Pagani (2014). From smoothed seismicity forecasts to probabilistic seismic hazard: insights and challenges from a global perspective, In: Proceeding of the 2nd European Conference on Earthquake Engineering and Seismology (Istanbul, August 24-29, 2014).

Weatherill, G., L. Rodriguez and M. Pagani (2014a). The Seismic Hazard Modelle's Toolkit: An Open-Source Library for the Construction of Probabilistic Seismic Hazard Models, In: Proceedings of the 2nd European Conference on Earthquake Engineering and Seismology (Istanbul, August 24-29, 2014).

Weatherill, G.A., M. Pagani and J. Garcia (2014b). OpenQuake Ground Motion Toolkit - User Guide. Global Earthquake Model (GEM), Technical Report; doi: 10.13117/ GEM.OPENQUAKE.MAN.GMTK.01.

Zhao, J.X., J. Zhang, A. Asano, Y. Ohno, T. Oouchi, T. Takahashi, H. Ogawa, K. Irikura, H.K. Thio, P.G. Somerville, Y. Fukushima and F. Fukushima (2006). Attenuation relations of strong ground motion in Japan using site classification based on predominant period, B. Seismol. Soc. Am., 96 (3), 898-913.

\section{Appendix}

\section{Useful links and on-line resources}

We provide herein a short summary of the resources accessible on-line for the different GEM hazard global components.

The personnel of the International Seismological Centre constantly update the ISC-GEM catalogue. The most recent version of the ISC-GEM catalogue can be downloaded from their website at the following link: http: / / www.isc.ac.uk/iscgem/ download.php (last accessed on September 2014).

The Global Historical Earthquake Catalogue and Archive can be accessed at the project website (http: / / www.emidius.eu/GEH/, last accessed on September 2014) where the catalogue can be also downloaded.

The GEM Global Strain Rate model (GSRM2) version 2.0 is accessible and downloadable from the UNAVCO website (http: / / gsrm2.unavco.org/, last accessed on September 2014). Version 2.1 of the GEM Global Strain Rate model is available on the GEM website (http: / / www.globalquakemodel.org/what/ seismichazard/strain-rate-model/, last accessed on September 2014).

The final report of the GEM Global GMPEs had been published as a joint PEER-GEM report and is available on the PEER website (http: / / peer.berkeley.edu / publications/peer_reports/reports_2013/webPEER2013-22-GEM.pdf, last accessed on September 2014). The reports of the different tasks can be downloaded from the web page dedicated to this project on the GEM website (http: / / www.globalquakemodel.org/what/ seismic-hazard/gmpes/, last accessed on September 2014).

The reports produced by the GEM Faulted Earth Project can be downloaded from Nexus, GEM's collaborative platform at the following link (http: / www.nex us.globalquakemodel.org/gem-faulted-earth/posts).

The GEM Hazard Modeller's Toolkit and the GEM Ground Motion Toolkit can be downloaded from Github at the following link: https: / / github.com/GEM ScienceTools (last accessed on September 2014).

The OpenQuake-engine and the GEM Hazard Library are available on GEM's area on Github: https: / / github.com/GEM (last accessed on September, 2014).

All the GEM datasets and PSHA input models will be accessible and downloadable from the GEM OpenQuake-platform, which will be publicly released at the end of 2014.

${ }^{\star}$ Corresponding author: Marco Pagani,

GEM Hazard Team, GEM Foundation, via Ferrata 1, Pavia, Italy; email: marco.pagani@globalquakemodel.org.

C 2015 by the Istituto Nazionale di Geofisica e Vulcanologia. All rights reserved. 